\title{
Influence of Centrifugal Shot Peening Parameters on the Impact Force and Surface Roughness of EN-AW 2024 Aluminum Alloy Elements
}

\section{Agnieszka Skoczylas ${ }^{1}$}

1 Department of Production Engineering, Mechanical Engineering Faculty, Lublin University of Technology, ul. Nadbystrzycka 36, 20-618 Lublin, Poland

e-mail: a.skoczylas@pollub.pl

\begin{abstract}
This article presents the results of experimental studies on the influence of centrifugal shot peening parameters on the impact force $F_{u}$ occurring during the machining of the EN - AW 2024 aluminum alloy. The surface roughness parameters $R a, R t, R p k, R v k$ and surface topography were also analyzed. Centrifugal shot peening was carried out on the FV-580a vertical machining center using a centrifugal shot peening head. Variable parameters of the centrifugal shot peening were: tangential speed $v_{g}$ and infeed $g$. On the basis of the results obtained, it was found that the increase the tangential speed $v_{g}$ and the infeed $g$ causes an increase of the impact force. After centrifugal shot peening, numerous micro-cavities were formed on the surface of the EN-AW 2024 aluminum alloy samples, which may can accumulate lubricants in their space. During centrifugal shot peening, low values impact force $F_{u}$ were obtained, which confirms the legitimacy of using this method as a finishing machining of elements with low stiffness.
\end{abstract}

Keywords: surface roughness, impact force, Centrifugal shot peening, EN-AW 2024 aluminum alloy

\section{INTRODUCTION}

One of the methods of finishing machining elements is burnishing and shot peening. It consists in using the phenomenon the local plastic deformation surface layer caused by the impact of a hard tool on the surface. This technology is successfully used in the technological process of producing such machine elements as: dies, moulds, shafts, compressor turbine blades, spring leaves, rear suspension control arms [1].

Burnishing allows obtaining a low surface roughness [7, 17] and modification of the surface roughness profile, which translates into an increase in the material ratio [5].

During shot peening the forces acting on the workpiece are much smaller compared to burnishing. This allows for machining of elements with low stiffness, e.g. thin-walled elements. The effect of shot peening, which includes centrifugal shot peening, is "knocking out" on the machined surface the cavities, which may constitute potentially "pockets" for accumulation of a lubricating medium in their space, which reduces the abrasive wear [4]. The shape of the micro asperities, which is more streamlined, contribute to the increased adsorption and chemical activity of the shot peened surface [12]. As a result of shot peening, the density increase and the concentration of crystal structure defects changes, which is confirmed by the studies that were carried out by annihilation techniques. The effect of these changes is an increase in the microhardness [2] and creation of compressive residual stresses in the surface layer $[19,22,14]$. Another advantage of shot peening is the possibility of increasing the fatigue strength and life of the elements subjected to variable loads $[13,18]$. The beneficial effect of shot peening, apart from improving the properties of the surface layer is also deburring and rounding of the workpiece edges [9]. Shot peening is also successfully used for machining Ti-6Al-4V 
implants produced by DMLS (direct metal laser sintering) additive technology [23, 24].

Centrifugal shot peening consists in hitting the machined surface with balls mounted radially in the holes of the rotating head. Centrifugal shot peened elements, protected from falling out, move radially during machining [21]. Centrifugal shot peening can be integrated with grinding [10].

Centrifugal shot peening is very often performed on numerically-controlled machining centers $[15,21]$. The occurrence of an impact motion during shot peening, and thus a component of the force perpendicular to the surface, may cause the loads on the machine tool spindle and contribute to the destruction of the tool. The knowledge of the force occurring during shot peening is important, especially when designing a technological process. There are no publications in the literature on the measurement of force during centrifugal shot peening. There are only studies on the measurement of forces during ball burnishing and sliding burnishing $[3,6,16]$.

The aim of this study was to assess the influence of technological parameters of centrifugal shot peening on the value of the impact force and surface roughness of the elements made of the EN-AW 2024 aluminum alloy.

\section{RESEARCH METHODOLOGY}

The research used the specimens made of the EN-AW 2024 aluminum alloy with the dimensions of $4 \times 15 \times 100 \mathrm{~mm}$. The EN-AW 2024 aluminum alloy is most commonly used in the manufacturing of airframes, wings sheathing, aircraft and car rims. It is also widely used for the structural components that require high strength at temperatures up to $150^{\circ} \mathrm{C}$, such as aircraft engine pistons and Diesel engine [11]. The specimens used in the experiment were pre-milled using R245-050022-DC50 milling head with a diameter of $d=50 \mathrm{~mm}$, equipped with R245-12F3 inserts. The following technological parameters process were used: cutting speed $v_{c}=$ $125 \mathrm{~m} / \mathrm{min}$, feed speed $v_{f}=200 \mathrm{~mm} / \mathrm{min}$, number of tooth $\mathrm{z}=4$. Figure 1 shows the research plan, which includes a set of variable, constant and output factors.

The centrifugal shot peening research was performed on an FV-580a vertical machining center. A special head with diameter $d_{g}=70 \mathrm{~mm}$, which in the housing has symmetrically arranged shot balls with a diameter $d_{k}=6.3 \mathrm{~mm}$ in the number $z_{k}=12$, was used as a tool. The kinematics of centrifugal shot peening on a vertical machining center is described in detail in [15]. The machining parameters (tangential speed $-v_{g}$, feed rate $-v_{f}$, infeed $-g$, cross-feed $-f_{p}$ ), selected on the preliminary research, were presented in Table 1 . The experiment for the given conditions was repeated seven times.

One of the variable parameters of centrifugal shot peening was the infeed $-g$, which is defined as the difference between the maximum head radius $\mathrm{R}_{\max }$ and the distance between the head axis and the machined surface $R$ (Fig. 2).

The impact force $F_{u}$, which is component perpendicular to the centrifugal shot penned surface, was measured with tensometric dynamometer. The force gauge consisted of a NA1 tensometric beam with a measuring range to $400 \mathrm{~N}$ and accuracy of $0.01 \mathrm{~N}$, and also and a 24-bit A/C HX 11 converter. The transducer in cooperation with the Arduino Nano mini controller allows saving the results in real time in the Microsoft Excel

Table 1. Centrifugal shot peening conditions used in the tests

\begin{tabular}{|c|c|c|c|}
\hline$v_{q}, \mathrm{~m} / \mathrm{min}$ & $g, \mathrm{~mm}$ & $v_{f} \mathrm{~mm} / \mathrm{min}$ & $f_{p}, \mathrm{~mm}$ \\
\hline 132 & & & \\
\cline { 1 - 1 } 264 & \multirow{2}{*}{0.45} & & \\
\cline { 1 - 1 } 396 & & \multirow{2}{*}{2304} & 0.08 \\
\hline 528 & & & \\
\cline { 1 - 2 } 396 & 0.35 & & \\
\cline { 1 - 2 } & 0.4 & & \\
\cline { 1 - 2 } & 0.5 & & \\
\hline
\end{tabular}

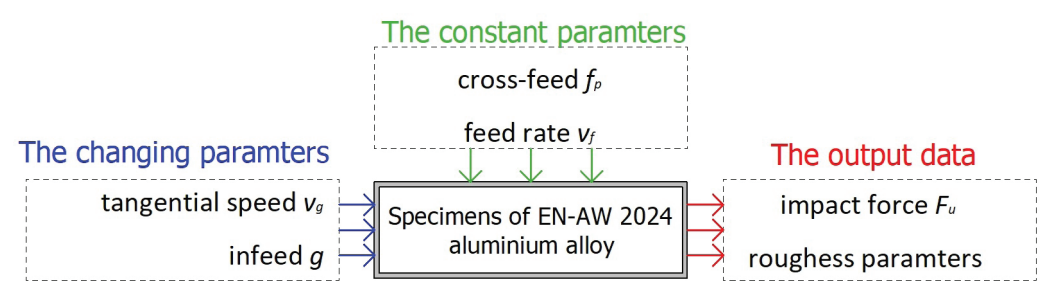

Figure 1. Research plan 


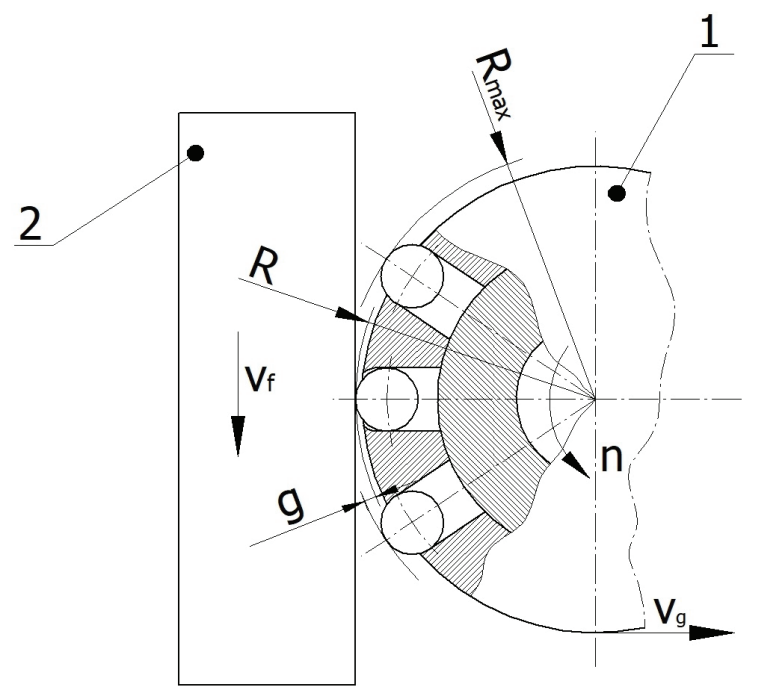

Figure 2. Scheme of the centrifugal shot peening and graphical interpretation of the infeed $g$ : 1 - centrifugal shot peening head, 2 - sample (where: $R_{\max }$ - maximum head radius, $R$ - distance between the head axis and the machined surface, $v_{g}-$ tangential speed, $v_{f}$ - feed rate, $n-$ speed of rotation $g-$ infeed

program [8]. The impact force $F_{u}$ is defined as the value at the moment, when the shot penned head contacts the workpiece surface.

The T8000RC 120-140 device from Hommel-Etamic was used for 2D surface roughness and 3D topography measurements. The scanned area was $4.8 \times 4.8 \mathrm{~mm}$. Hommel Map Basic version 6.2 was used to determine 3D surface roughness parameters.

\section{RESULTS}

Figure 3 shows an example of the force as a function of the sampling time. There are three characteristic stages of the tool work: the entry zone, the stable work zone and the exit zone. At the moment of the impact of ball on the surface of the workpiece, the force increases rapidly and this is the impact force $F_{u}$, next it decreases and stabilizes at a certain level (it is most likely the value of the friction force between the system components). The lack of contact between the ball and the workpiece in the exit zone causes that the force value decreases to zero.

The impact force $F_{u}$ increases along with the rotational speed $n$, and thus tangential speed of the head $v_{g}$ (Fig. 4). It is related to the increase of the collision energy, which occurs with the increase of speed $v_{g}$. The higher the collision energy translates into larger the degree of deformation machined surface, which creates greater resistance. The $400 \%$ increase the $v_{g}$ speed cause the $F_{u}$ impact force to increase by about $950 \%$. The

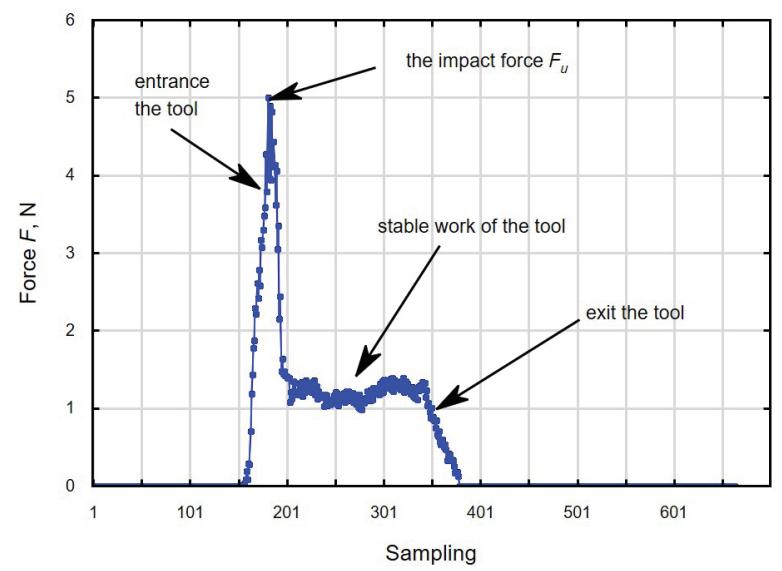

Figure 3. The course of the force during centrifugal shot peening $\left(v_{g}=528 \mathrm{~m} / \mathrm{min}, g=0.45 \mathrm{~mm}\right)$ 


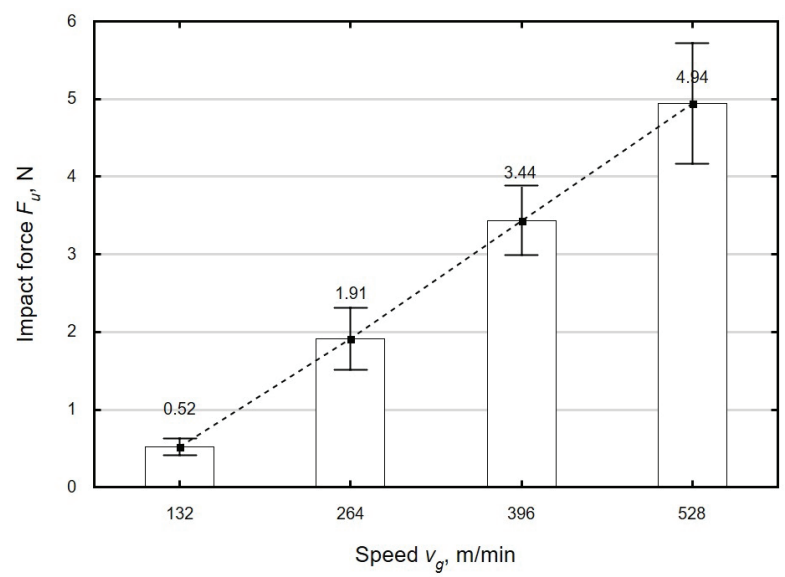

Figure 4. The influence the tangential speed $v_{g}\left(g=0.45 \mathrm{~mm}, v_{f}=2304 \mathrm{~mm} / \mathrm{min}, f_{p}=0.08 \mathrm{~mm}\right)$ on the impact force $F_{u}$

highest standard deviation occurs for the maximum value of the speed $v_{g}$, which may suggest that the character of the work is less stable for this speed.

The figure 5 presents the influence of infeed $g$ on the tested variable. While analyzing the obtained results, it should be noted that an increase of infeed $g$ in the range from 0.35 to $0.45 \mathrm{~mm}$ caused an increase of the impact force $F_{u}$. A further increase of infeed led to slight changes the $F_{u}$ value. It can be assumed that the change of the infeed in the upper value will have lesser influence on the durability of the head than the tangential speed $v_{g}$.

The face milling was the pre-machining before centrifugal shot peening. An exemplary topography and surface profile were presented in Figure 6. On the milled surface there is unidirectional pattern of micro asperities, which have similar height with characteristic trace of the work the edge. The surface shows "peaks" and "valleys", which are the result of mapping the work of the tool nose. The resulting surface should be classified as unidirectional anisotropic.

The roughness parameter $R a$ is most often used to assess the surface quality, but it is difficult to evaluate the stereometric properties of the surface on the basis of its value. The value the total height of the profile $R t$ allows for the prediction of the occurrence the peaks and valleys in the machined surface.

The figure 7 shows the influence of the tangential speed $v_{g}$ on the surface roughness parameters $R a$ (Fig. $7 \mathrm{~g}$ ) and $R t$ (Fig. 7b) after centrifugal shot peening. The increase of speed $v_{g}$ causes the enhanced kinetic energy, which influences the size of the elastic-plastic deformations of the surface irregularities. The occurring deformations determine the surface roughness, which translates into an increase in the analyzed variables.

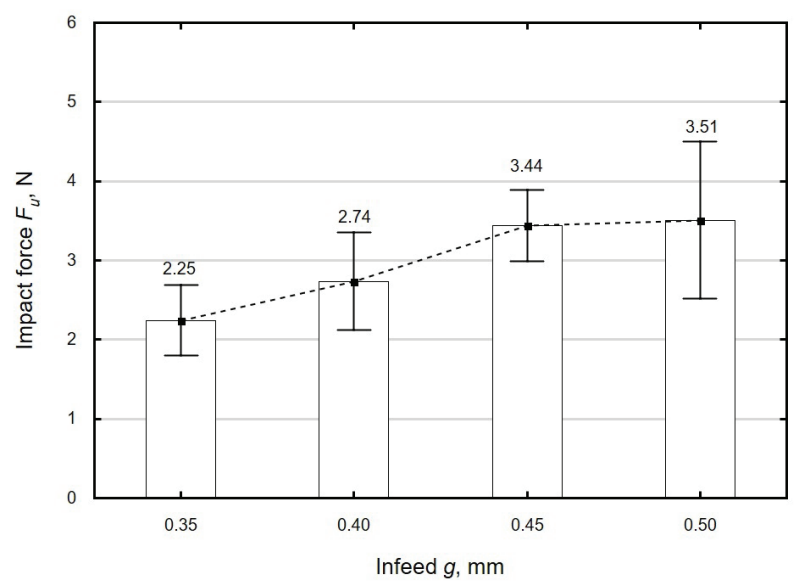

Figure 5. The influence infeed $g\left(v_{g}=396 \mathrm{~m} / \mathrm{min}, v_{f}=2304 \mathrm{~mm} / \mathrm{min}, f_{p}=0.08 \mathrm{~mm}\right)$ on the impact force $F_{u}$ 
a)

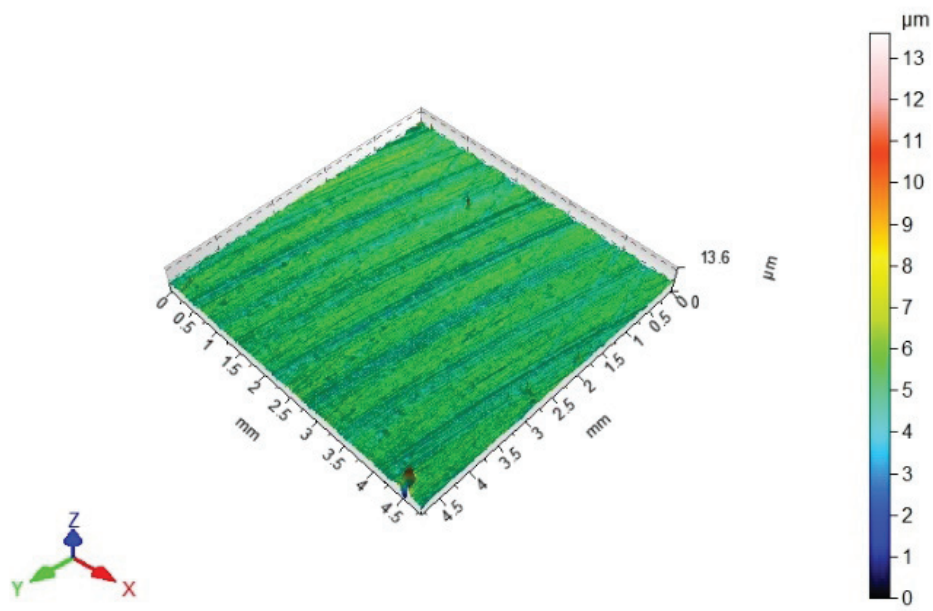

b)

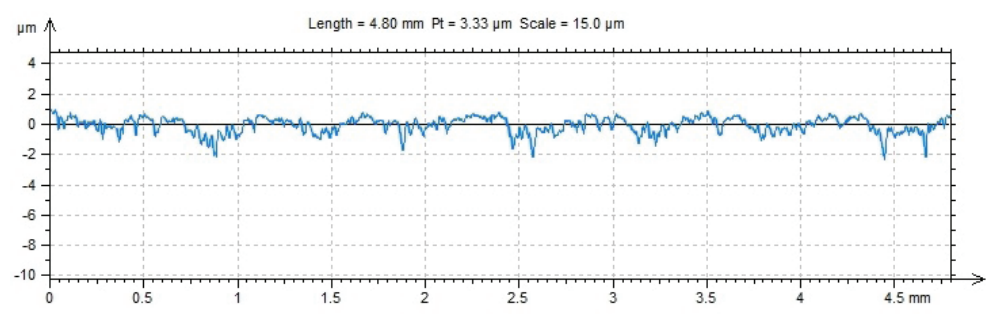

Figure 6. The surface topography (a) and surface profile (b) of the EN-AW 2024 aluminum alloy samples after milling

The largest changes in the roughness parameter $R a$ and $R t$ are visible for the speed range $v_{\alpha}=$ $264 \div 396 \mathrm{~m} / \mathrm{min}$. The $R a$ values are from $23 \%$ to $82 \%$ higher than after milling. In the case of the $R t$ parameter, the maximum increase of this parameter was achieved by about $9 \%$ compared to the value after milling.

During centrifugal shot peening for speed $v_{g}$ in the range from $132 \mathrm{~m} / \mathrm{min}$ to $396 \mathrm{~m} / \mathrm{min}$ on the machined surface traces, which the reduced height of the peaks $(R p k)$ increase, while the reduced depth of the valleys $(R v k)$ decrease, as a function of the analyzed variable (Fig. 8). The changes that occur are most likely related to the properties of the tested material and the character of "contact" of the tool with the centrifugal shot peened surface. The EN-AW 2024 aluminum alloy is a material susceptible to the elastic-plastic deformation. The high friction occurs between the peened surface and the shot balls, which is caused by a wide angle between the normal velocity vector and the peened surface [15]. The a)

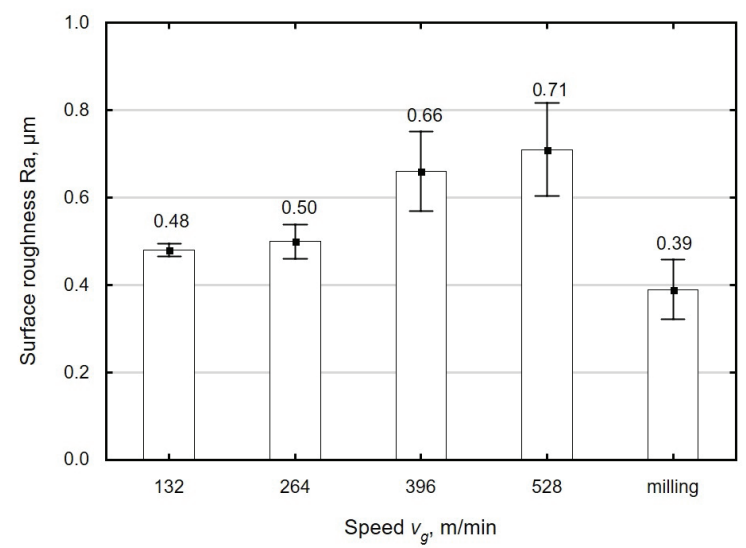

b)

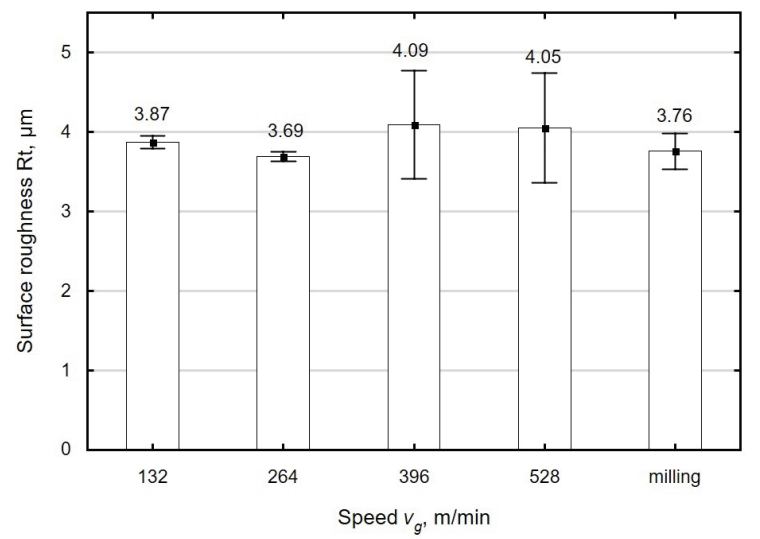

Figure 7. The influence the tangential speed $v_{g}$ on the roughness parameters $R a$ (a) and $R t$ (b) $\left(g=0.45 \mathrm{~mm}, v_{f}=2304 \mathrm{~mm} / \mathrm{min}, f_{p}=0.08 \mathrm{~mm}\right)$ 


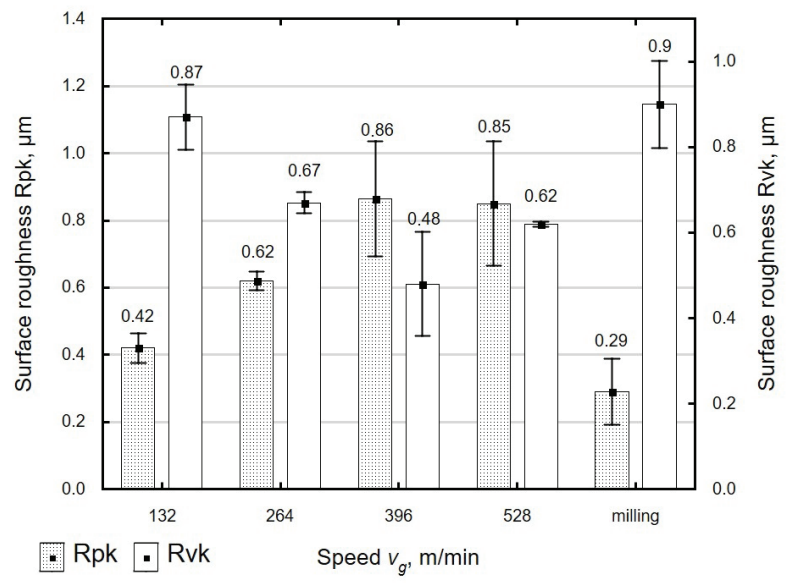

Figure 8. The influence the tangential speed $v_{g}$ on the roughness parameters $R p k$ and $R v k$ $\left(g=0.45 \mathrm{~mm}, v_{f}=2304 \mathrm{~mm} / \mathrm{min}, f_{p}=0.08 \mathrm{~mm}\right)$

intense impact of shot balls and the material susceptibility to deformation favor the formation of micro-cavities, which have intensely deformed sharp peaks of high height and deformed valleys. In the range of $v_{g}=396 \div 528 \mathrm{~m} / \mathrm{min}$, there were no significant changes in the $R v k$ parameter, while the $R p k$ parameter increased.

The change of the infeed in the range of $g=0.35 \div 0.4 \mathrm{~mm}$ causes a decrease in the values of the analyzed roughness parameters $R a$ and $R t$ (Fig. 9). However, a further increase of infeed caused a slight increase in the $R a$ and $R t$ parameter. A similar character of changes was observed for the reduced height of the peaks $R p k$ and the reduced depth of the valleys $R v k$ (Fig. 10). An increase the infeed causes that the shot balls hit the machined surface from a shorter distance, but with higher force $F_{u}$ (Fig. 5). This causes an intensive deformation of the centrifugal shot peened

a)

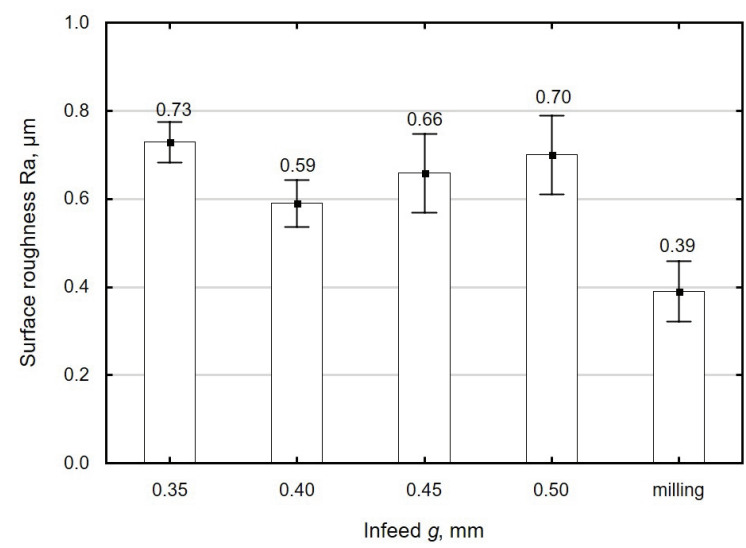

surface. The smaller changes of the analyzed variables were observed for large infeed values. This is due the greater hardening of the material, which makes it more resistant to plastic deformation. The smallest value of the analyzed parameters were obtained for the infeed $g=0.4 \mathrm{~mm}$.

The use of centrifugal shot peening for samples made of the EN-AW 2024 aluminum alloy resulted in an increase in the analyzed roughness parameters $R a, R t, R p k$ in relation to the surface after milling. A beneficial effect obtained by centrifugal shot peening, despite the decrease the value of the Rvk parameter, is the change the shape of the micro-cavities. The resulting machining traces (Fig. 11a and 11b) have a spherical shape, which suggests that they can become potential "pockets" capable of accumulating lubricants. The increase the retention capacity of the centrifugally shot peened surface may contribute to the reduction of abrasive wear [20].

b)

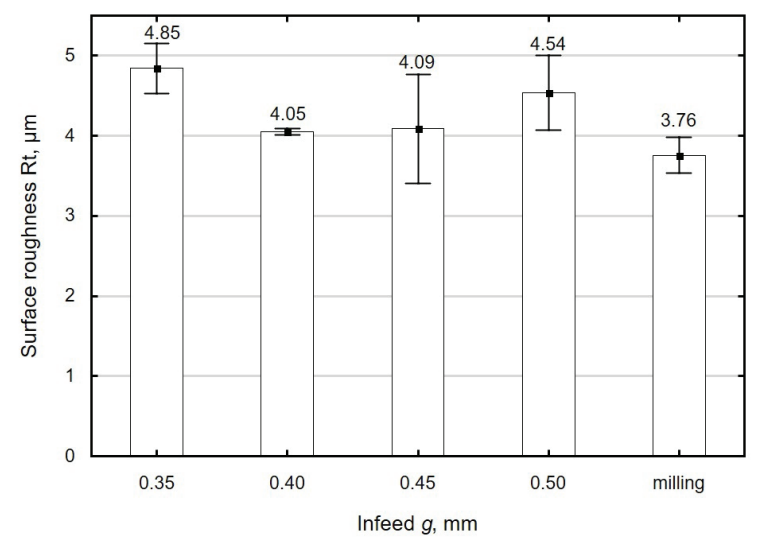

Figure 9. The influence infeed $g$ on the roughness parameters $R a$ (a) and $R t(\mathrm{~b})$ $\left(v_{g}=396 \mathrm{~m} / \mathrm{min}, v_{f}=2304 \mathrm{~mm} / \mathrm{min}, f_{p}=0.08 \mathrm{~mm}\right)$ 


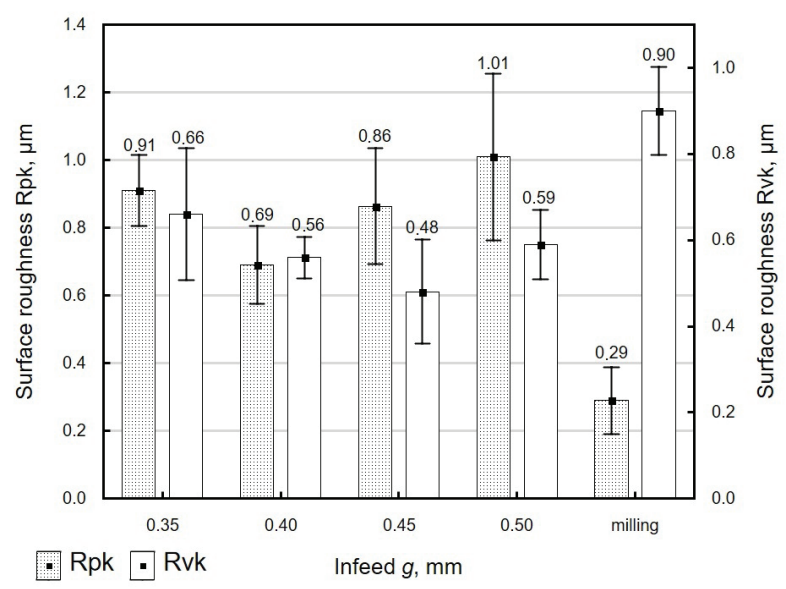

Figure 10. The influence infeed $g$ on the roughness parameters $R p k$ and $R v k$ $\left(v_{g}=396 \mathrm{~m} / \mathrm{min}, v_{f}=2304 \mathrm{~mm} / \mathrm{min}, f_{p}=0.08 \mathrm{~mm}\right)$

a)

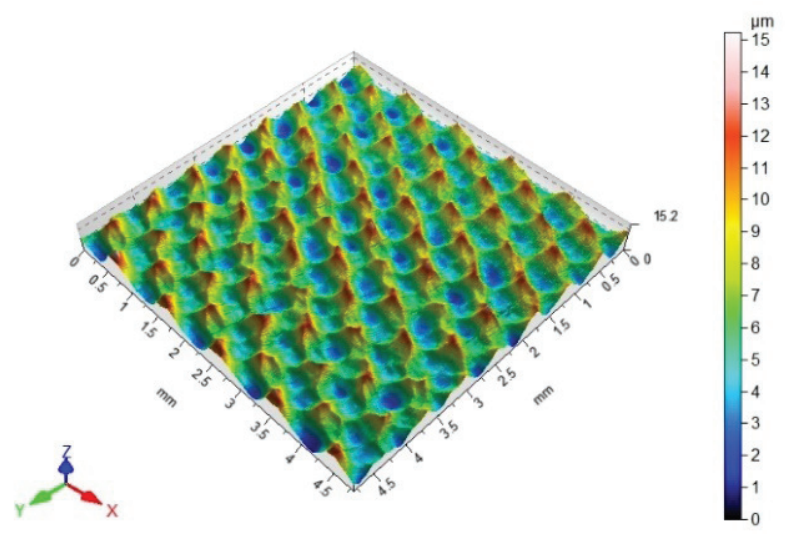

b)

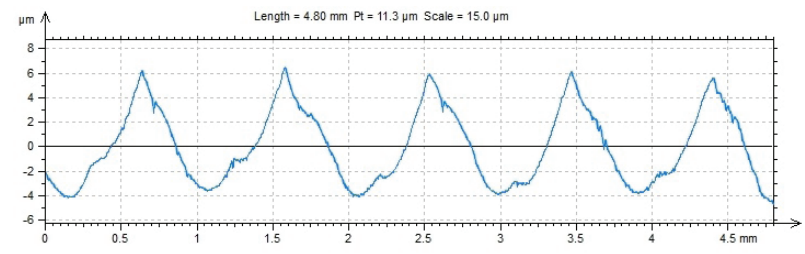

Figure 11. The surface topography (a) and surface profile (b) of EN-AW 2024 aluminum alloy samples after centrifugal shot peening $\left(v_{g}=528 \mathrm{~m} / \mathrm{min}, g=0.45 \mathrm{~mm}, v_{f}=2304 \mathrm{~mm} / \mathrm{min}, f_{p}=0.08 \mathrm{~mm}\right)$

\section{CONCLUSIONS}

On the basis of the conducted research of centrifugal shot peening of the elements made of the EN-AW 2024 aluminum alloy, the following conclusions can be drawn:

1. The impact force $F_{u}$, occurring during centrifugal shot peening, does not reach high values in the range of the analyzed technological parameters.

2. An increase the tangential speed $v_{g}$ and the infeed $g$ causes an increase in the value of the analyzed force $F_{u}$. The changes are more visible for the tangential speed of the head $v_{g}$ in the analyzed range than for the infeed $g$.

3. The surface roughness of the elements from the EN-AW 2024 aluminum alloy slightly increase after centrifugal shot peening.

4. After centrifugal shot peening, only the $R v k$ parameter is reduced in relation to the value following milling. As a result of centrifugal shot peening, the shape of the surface profile valley also changed.

5. During centrifugal shot peening, low values of impact force $F_{u}$ occur, which confirms the possibility of using this method of as a finishing machining of elements with low stiffness. 


\section{REFERENCES}

1. Avilés, R., Albizuri, J., Rodríguez, A., López de Lacalle, L.N.: Influence of low-plasticity ball burnishing on the high-cycle fatigue strength of medium carbon AISI 1045 steel. International Journal of Fatigue, 55, 2013, 230-244.

2. Cho K.T., Song K., Oh S.H., Lee Y.K., Lim K.M., Lee W.B.: Surface hardening of aluminum alloy by shot peening treatment with $\mathrm{Zn}$ based ball. Materials Science and Engineering A, 534, 2012, 44-49.

3. Dzionk S., Ścibiorski B., Waszczur P., Przybylski W.: The forces occurring in the ball burnishing and sliding burnishing process. Mechanik, R. 87, 11, 2014, 70-79 (in Polish).

4. Galda L., Sep J., Prucnal S.: The effect of dimples geometry in the sliding surface on the tribological properties under starved lubrication conditions. Tribology International, 99, 2016, 77-84.

5. Grzesik W., Żak K., Chudy R., Prażmowski M., Małecka J.: Optimization of subtractive-trans formative hybrid processes supported by the technological heredity concept. CIRP Annals - Manufacturing Technology, 68, 2019, 101-104.

6. Hongyun L., Jianying L., Lijiang W., Qunpeng Z.: The effect of burnishing parameters on burnishing force and surface microhardness. The International Journal of Advanced Manufacturing Technology, 28, 2006, 707-713.

7. Maheshwari A.S., Gawande R.R.: Influence of specially designed high-stiffness ball burnishing tool on surface quality of titanium alloy. Materials Today: Proceedings, 4, 2017, 1405-1413.

8. Matuszak J., Kłonica M., Zagórski I.: Measurements of forces and selected surface layer properties of AW-7075 aluminum alloy used in the aviation industry after abrasive machining. Materials, 12(22), 2019, 3707.

9. Matuszak J., Zaleski K.: Analysis of deburring effectiveness and surface layer properties around edges of workpieces made of 7075 aluminium alloy. Aircraft Engineering and Aerospace Technology, vol. 90, No. 3, 2018, 515-523.

10. Nadolny K., Plichta J., Radowski M.: Reciprocal internal cylindrical grinding integrated with dynamic centrifugal burnishing of hard-to-cut materials. Proceedings of the Institution of Mechanical Engineers, Part E: Journal of Process Mechanical Engineering, 22(4), 2015, 265-279.

11. Oczoś K.E., Kawalec A. Kształtowanie metali lekkich. Wydawnictwo Naukowe PWN, Warszawa, 2012 (in Polish)

12. Rudawska A., Zaleski K., Miturska I., Skoczylas A.: Effect of the application of different surface treatment methods on the strength of titanium alloy sheet adhesive lap joint. Materials, 12(24), 2019, 4173.
13. Sahoo B., Satpathy R.K., Prasad K., Ahmed S., Kumar V.: Effect of shot peening on low cycle fatigue life of compressor disc of a typical fighter class aero-engine. Procedia Engineering, 55, 2013, 144-148.

14. Sasikumar K.S.K., Dineshkumar K., Deeban K., Sambathkumar M., Saravanan N.: Effect of shot peening on surface properties of A17075 hybrid aluminum metal matrix composites. Materials Today: Proceedings, article in press, 2020.

15. Skoczylas A., Zaleski K.: Effect of Centrifugal Shot Peening on the Surface Properties of Laser-Cut C45 Steel Parts. Materials, 12(21), 2019, 3635.

16. Stöckmann R., Posdzich M., Klimant P., Putz M.: Influence of the stiffness of burnishing tools on process force and surface quality of EN AW-2007 and C45 workpieces. Procedia Manufacturing, 43, 2020, 635-641.

17. Świrad S., Wydrzynski D., Nieslony P., Krolczyk G.M.: Influence of hydrostatic burnishing strategy on the surface topography of martensitic steel. Measurement, 138, 2019, 590-601.

18. Walker J., Thomas D.J., Gao Y.: Effects of shot peening and pre-strain on the fatigue life of dual phase Martensitic and Bainitic steels. Journal of Manufacturing Process 26, 2017, 419-424.

19. Wiertel M., Zaleski K., Gorgol M., Skoczylas A., Zaleski R.: Impact of impulse shot peening parameters on properties of stainless steel surface. Acta Physica Polonica A., 132(5), 2017, 1611-1615.

20. Zaleski K.: The effect of vibratory and rotational shot peening and wear on fatigue life of steel. Eksploatacja i Niezawodność Maintenance and Reliability, 19(1), 2017, 102-107.

21. Zaleski K., Skoczylas A., Ciecielag K.: The Investigations of the Surface Layer Properties of C45 Steel After Plasma Cutting and Centrifugal Shot Peening. [In]: Industrial Measurements in Machining, Lecture Notes in Mechanical Engineering, eds. Królczyk Grzegorz M., Niesłony P., Królczyk J., Springer, 2020, 172-185

22. Zaleski R., Zaleski K., Gorgol M., Wiertel M.: Positron annihilation study of aluminium, titanium, and iron alloys surface after shot peening. Applied Physics A, 120, 2015, 551-559.

23. Żebrowski R., Walczak M., Korga A., Iwan M., Szala M.: Effect of Shot Peening on the Mechanical Properties and Cytotoxicity Behaviour of Titanium Implants Produced by 3D Printing Technology. Journal of Healthcare Engineering, 2019, 1-11.

24. Żebrowski R., Walczak M., Klepka T., Pasierbiewicz K.: Effect of the shot peening on surface properties of Ti-6Al-4V alloy produced by means of DMLS technology. Eksploatacja i Niezawodność Maintenance and Reliability, 21(1), 2019, 46-53. 